\title{
RESEARCH
}

Open Access

\section{Stem cells from human exfoliated deciduous teeth correct the immune imbalance of allergic rhinitis via Treg cells in vivo and in vitro}

Yu-Yang Dai ${ }^{1,2}$, Si-Yang Ni ${ }^{1}$, Ke Ma ${ }^{3}$, Yu-Shi Ma ${ }^{4}$, Zhi-Shi Wang ${ }^{4}$ and Xiu-Li Zhao ${ }^{1 *}$ (D

\begin{abstract}
Background: Several studies have demonstrated that mesenchymal stem cells can ameliorate the inflammation of allergic rhinitis (AR) and correct the Th1/Th2 immune imbalance.

Methods: This study was performed to explore the immunomodulation properties of stem cells from human exfoliated deciduous teeth (SHEDs) in the treatment of AR in vivo and in vitro. BALB/c mice were sensitized to ovalbumin (OVA) by intraperitoneal injection, and then SHEDs or bone marrow mesenchymal stem cells (BMMSCs) were injected intravenously before challenge. We evaluated nasal symptoms, inflammatory infiltration of nasal mucosa, immunoglobulin secretion, cytokine production, and mRNA expression in the spleen. In addition, peripheral blood mononuclear cells (PBMCs) from AR patients were cultured with SHEDs or BMMSCs in the presence of phytohemagglutinin (PHA). PBMCs cultured alone with or without PHA served as controls. After 3 days of culture, we examined the effect of SHEDs on T lymphocyte proliferation, cytokine secretion, and the proportion of Foxp3 ${ }^{+}$Treg cells via flow cytometry. Finally, to determine the role of soluble factors (TGF- $\left.\beta_{1}, P G E_{2}\right)$ in the immunomodulatory mechanism, a cytokine neutralization assay was performed.
\end{abstract}

Results: Nasal symptoms and inflammatory infiltration were significantly reduced after SHED administration. The OVAspecific IgE and IgG levels in serum were significantly decreased, and the increased IL-4, IL-5, IL-13, and IL-17A levels in the spleen after OVA challenge were markedly downregulated, while the level of IFN- $\gamma$ was upregulated by SHED administration. The mRNA expression levels also changed correspondingly. SHEDs significantly inhibited the proliferation of T lymphocytes; increased the levels of IFN-Y, IL-10, PGE 2 , and TGF- $\beta_{1}$; decreased the levels of IL-4 and IL-17A; and induced the expansion of Treg cells in the coculture system. The neutralization of TGF- $\beta_{1}$ partly relieved the immunosuppression of SHEDs, but blocking $\mathrm{PGE}_{2}$ did not. In addition, SHEDs were superior to BMMSCs in inhibiting the Th2 immune response in vivo and inducing the expansion of Treg cells in vitro.

Conclusion: These results suggest that SHEDs could correct the $C D 4^{+} T$ cell immune imbalance via Treg cells and may be potential therapeutic agents for the treatment of allergic diseases, such as AR, in the future.

Keywords: Allergic rhinitis, Stem cells from human exfoliated deciduous teeth, Regulatory T cells, Transforming growth factor beta, Immunoregulation

\footnotetext{
* Correspondence: lilyzhao1028@outlook.com

${ }^{1}$ National Institute for Drug Clinical Trial, Beijing Tongren Hospital, Capital

Medical University, 1 Dongjiaominxiang Road, Beijing 100730, China

Full list of author information is available at the end of the article
}

(c) The Author(s). 2019 Open Access This article is distributed under the terms of the Creative Commons Attribution 4.0 International License (http://creativecommons.org/licenses/by/4.0/), which permits unrestricted use, distribution, and reproduction in any medium, provided you give appropriate credit to the original author(s) and the source, provide a link to the Creative Commons license, and indicate if changes were made. The Creative Commons Public Domain Dedication waiver (http://creativecommons.org/publicdomain/zero/1.0/) applies to the data made available in this article, unless otherwise stated. 


\section{Background}

Allergic rhinitis (AR) is an allergic inflammatory reaction characterized by sneezing, itching, rhinorrhea, and nasal blockage. The incidence of AR has increased in recent years, and it seriously impacts the quality of life and work efficiency of patients [1]. Pharmacotherapy, such as intranasal corticosteroids, antihistamines, and leukotriene antagonists, can reduce allergic symptoms, and allergen immunotherapy can be employed if patients are resistant to the usual therapy. Immunotherapy involves a regular injection of incremental doses of allergen vaccines to induce allergen tolerance. However, immunotherapy is restricted by allergen types, and the long treatment cycle usually results in poor compliance in clinical settings.

In recent years, experimental and clinical evidence have indicated that mesenchymal stem cells (MSCs) possess significant immunomodulatory and nonimmunogenic properties in the treatment of several immune diseases, including asthma, multiple sclerosis, Crohn's disease, graft-versus-host disease, and other inflammatory disorders [2-4]. MSCs have been proposed as a new approach for AR treatment as they are able to reduce eosinophil infiltration in the nasal mucosa and regulate the release of cytokines to control the $\mathrm{CD} 4^{+} \mathrm{T}$ cell response [5-7]. However, the main problem at present is to find the suitable tissue source from which MSCs can be achieved by immune regulation, security, easy access, low cost, and no ethical hurdles.

MSCs were first found in the bone marrow, namely bone marrow mesenchymal stem cells (BMMSCs). The immunomodulatory ability of BMMSCs has been verified in various allergic disease models with typicality and representativeness [8]. Nevertheless, the acquisition of BMMSCs is difficult along with invasive operations. The content of MSCs in bone marrow is relatively low, and the quantity and differentiation capacity reasonably decrease with age [9]. Fortunately, after the first isolation of MSCs from bone marrow, further studies demonstrated that other tissues also contain MSCs. To date, MSCs can be obtained more easily from many tissues, such as adipose tissue, umbilical cord, kidney, lymph nodes, and dental pulp. Among them, stem cells from human exfoliated deciduous teeth (SHEDs) are drawing attention. SHEDs were first isolated from children's deciduous teeth [10], which are regarded as medical waste. Compared with BMMSCs, they are easily obtained and are free from the ethical concerns. The dental pulp from deciduous teeth exists before birth and until permanent teeth eruption, SHEDs are considered more immature than other postnatal MSCs. Besides all, SHEDs are MSCs with a more proliferative capacity than BMMSCs [11]. Up to now, several SHED banks have been established worldwide. SHEDs are relatively new and less studied than MSCs from other sources. Few studies have investigated the immunomodulatory properties of SHEDs in AR models. In this study, we addressed the immunomodulatory effects of SHEDs on a murine model of AR and a cell coculture system, providing a basis for further clinical applications of MSCs in treating allergic diseases.

\section{Methods}

\section{Expansion of SHED and BMMSC in vitro}

Three frozen tubes of SHEDs (passage 2) were kindly provided from Tason Biotech Co., Ltd. (Beijing, China) for this research study. These cells had been isolated from the pulp tissues of exfoliated deciduous teeth in children aged 6-8 years. The immunophenotyping $\left(\mathrm{CD} 11 \mathrm{~b}^{-} / \mathrm{CD} 19^{-} / \mathrm{CD} 4^{-} / \mathrm{CD} 45^{-} / \mathrm{CD}^{+} 3^{+} / \mathrm{CD} 0^{+} / \mathrm{CD} 105^{+}\right)$ and capacity of differentiation (osteoblast induction) were confirmed by the supplier. SHEDs were seeded into T75 flasks, cultured in complete medium containing alpha modification of Eagle's medium ( $\alpha$-MEM; Invitrogen, Carlsbad, CA, USA) supplemented with $15 \%$ fetal bovine serum (FBS; Invitrogen), $2 \mathrm{mM} \mathrm{L}$-glutamine (Invitrogen), $100 \mu \mathrm{M}$ L-ascorbic acid 2-phosphate (Sigma, St. Louis, MO, USA), and 1\% penicillin/streptomycin (Invitrogen) for further passages. The culture medium was changed every 3 to 4 days, and the cells were again trypsinized and cultured for additional passages when they reached $80 \%$ confluency. When SHEDs were cultured to passage 4, 15\% FBS was replaced with $10 \%$ FBS. These steps were repeated until a sufficient number of SHEDs (passage 6) were collected for further experiments.

BMMSCs were purchased as a T25 cell culture flask (passage 2) from Lonza (Basel, Switzerland). To obtain the required number of cells, BMMSCs were cultured in complete Dulbecco's modified Eagle's medium/nutrient F-12 Ham (DMEM/F12; Invitrogen) supplemented with $10 \%$ FBS, $2 \mathrm{mM}$ L-glutamine, and 1\% penicillin/streptomycin, and cells were also expanded in vitro as SHEDs.

\section{AR mouse model}

Female BALB/c mice (6-8 weeks of age), free of murine-specific pathogens, were purchased from Vital River Laboratory Animal Technology Co., Ltd. (Beijing, China). The mice were housed in a controlled environment under a 12/12-h light/dark cycle with free access to food and water. The animal study protocol was approved by the Institutional Animal Care and Use Committee of Capital Medical University (AEEI-2018-075).

AR mouse models were sensitized using ovalbumin (OVA, grade V; Sigma) and alum (Pierce, Rockford, IL, USA) as previously reported with minor modification [12]. Briefly, mice were sensitized on days 0,7 , and 14 via intraperitoneal injection of $25 \mu \mathrm{g}$ OVA emulsified in 
$2 \mathrm{mg}$ alum in a total volume of $100 \mu \mathrm{l}$ phosphate-buffered saline (PBS). On days 21 to 27 after the initial sensitization, these mice were challenged by the daily intranasal instillation of $100 \mu \mathrm{g}$ OVA in $20 \mu \mathrm{l}$ PBS using a micropipette. The mice were sacrificed via cervical dislocation under anesthesia at day 28 (Fig. 1).

\section{Xenograft of SHEDs or BMMSCs into AR mouse model}

SHEDs or BMMSCs (passage 4) were washed and suspended in PBS at a concentration of $5 \times 10^{6}$ cells $/ \mathrm{ml}$, and $100 \mu \mathrm{l}$ of purified stem cells was injected with a 26 -gage needle into the mouse tail vein on days 18,19 , and 20 (Fig. 1). Thirty mice were divided into five groups of six mice, each in accordance with the different interventions of sensitization, challenge, and injection as follows: (1) control group, sensitized and challenged with PBS and injected with PBS; (2) sham-SHED group, sensitized and challenged with PBS and injected with SHEDs; (3) OVA group, sensitized and challenged with OVA and injected with PBS; (4) SHED group, sensitized and challenged with OVA and injected with SHEDs; (5) BMMSC group, sensitized and challenged with OVA and injected with BMMSCs.

\section{Nasal allergic symptoms}

On day 27, during the 10-min period after the final administration of intranasal OVA, the frequencies of sneezing and nasal rubbing were recorded by two observers in a blind manner as previously reported [13].

\section{Histologic analysis and immunohistochemistry}

The mice were sacrificed $24 \mathrm{~h}$ after the last OVA challenge. Nasal mucosa was removed, washed with PBS, and immersed in $4 \%$ buffered paraformaldehyde for 24 h. After fixation, the specimens were embedded in paraffin wax and sectioned serially at a thickness of $4 \mu \mathrm{m}$.
Sections were stained with hematoxylin and eosin (HE) and periodic acid-Schiff (PAS) respectively and observed under a light microscope (×400 magnification). HE staining was performed to evaluated eosinophil infiltration. Eosinophils were morphologically defined by the presence of eosinophilic granules (red) that were stained by eosin in the cytoplasm and the presence of a two-lobed nucleus. The numbers of eosinophils were evaluated in four randomly selected fields by two observers blinded to the experiment. PAS staining was used to estimate goblet cell hyperplasia and mucus production. Positive-goblet cells were stained purple-magenta color under the microscope.

To analyze $\mathrm{T}$ lymphocyte infiltration, immunohistochemistry (IHC) procedure was performed using Elivision method. Briefly, after deparaffinization and rehydration, endogenous peroxidase activity was quenched with $3 \%$ hydrogen peroxide. Sections were heated for $3 \mathrm{~min}$ in a citrate buffer $(10 \mathrm{mmol} / \mathrm{L}, \mathrm{pH} 6.0)$ to retrieve antigen. After goat serum blocking for 20 min, sections were incubated with the primary polyclonal antibody, rabbit anti-mouse CD3e (1:200; Cat.No. PA5-32318; Invitrogen), overnight at $4{ }^{\circ} \mathrm{C}$ to stain target protein expression. Following 20-min incubation with secondary anti-rabbit antibody, 3.3-diaminobenzidine (Sigma) was applied for visualizing immunoreactivity, and counterstaining was performed with Mayer hematoxylin. The cytoplasm of the positive $\mathrm{T}$ lymphocytes was stained brown.

Detection of serum OVA-specific $\lg E_{1} \lg G_{1}$, and $\lg _{2 a}$

The blood samples were collected from mice via eyeball extraction $24 \mathrm{~h}$ after the last OVA challenge. Serum

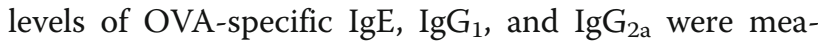
sured by ELISA kits (BD Bioscience, San Jose, CA, USA) in accordance with the manufacturer's instructions.

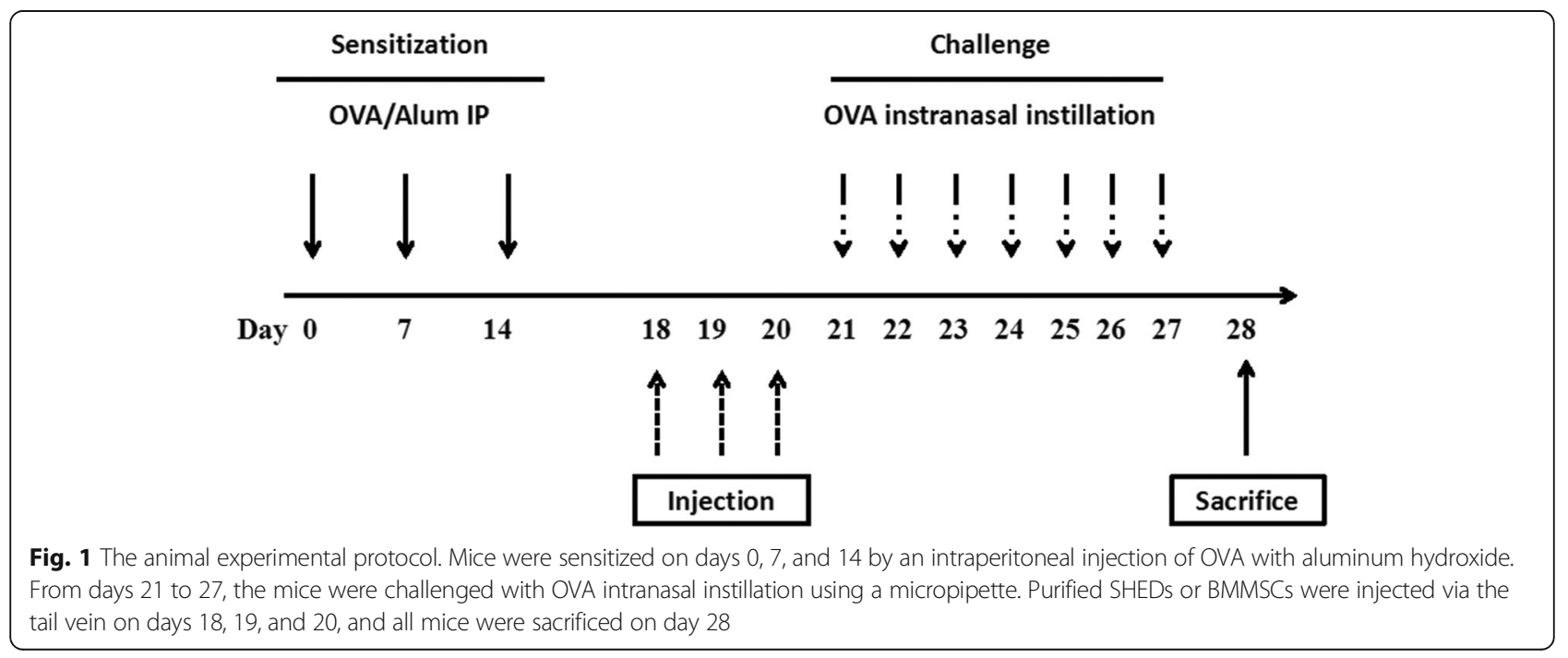




\section{Expression of cytokines in the spleen}

Fresh spleens were separated from the mice in aseptic conditions after sacrifice. The spleen was placed in a petri dish containing RPMI 1640 medium, and a syringe was used to crush the tissue before filtration through a $70-\mu \mathrm{m}$ filter. The splenocytes were treated with lysis buffer to deplete erythrocytes. Single-cell suspensions of splenocytes $\left(1 \times 10^{5}\right.$ cells/well in 96-well culture plates) were cultured in completed RPMI 1640 medium supplemented with $10 \% \mathrm{FBS}, 2 \mathrm{mM}$ L-glutamine, and restimulated with OVA $(100 \mathrm{ng} / \mathrm{ml})$. After 3 days of culture, interleukin (IL)-4, IL-5, IL-13, and IL-17A and interferon (IFN)- $\gamma$ levels in the culture supernatant were measured using an ELISA kit (BD Bioscience) following the manufacturer's instructions.

Quantitative real-time polymerase chain reaction analysis Total RNA was extracted from the spleen using the TRIzol reagent kit (Invitrogen) for messenger RNA (mRNA) relative expression analysis of IFN- $\gamma$, T-bet, IL-4, GATA-3, IL-17A, RORyt, and Foxp3. Equivalent amounts of RNA were reverse transcribed using the PrimeScript RT Reagent Kit (Takara, Tokyo, Japan). The mRNA expression analysis was performed using an Applied Biosystem 7500 Real-Time PCR System (Applied Biosystems, Foster City, CA, USA). The corresponding primers and probes for the cytokines and chemokines are listed in Additional file 1: Table S1. The average transcript levels of genes were normalized to $\beta$-actin. The relative mRNA gene expression was calculated using the $2^{-\Delta \Delta C t}$ method.

\section{Coculture of SHEDs with PBMCs}

To investigate the underlying mechanism of the SHED immunomodulatory effect, we carried out coculture experiments of MSCs with human peripheral blood mononuclear cells (PBMCs). PBMCs were isolated from heparinized peripheral blood of 20 AR patients using Ficoll-Paque (Amersham Biosciences, NJ, USA). The diagnosis of seasonal AR was established according to the criteria of the Allergic Rhinitis and its Impact on Asthma (ARIA) [14] based on clinical symptoms, nasal endoscopy examination, and serum IgE allergen detection. The patients did not receive intranasal steroids, antihistamines, or leukotriene blocker treatments within 1 week or oral steroids within 3 months prior to this study. The Ethics Committee of Beijing Tongren Hospital, Capital Medical University approved this study (TREC2018-KY01), and informed consent was obtained from all participants.

Coculture experiments $(n=10)$ were performed in a 24-well plate, and both types of human MSCs were treated with mitomycin (incubation for $2 \mathrm{~h}$ at $10 \mu \mathrm{g} / \mathrm{ml}$ ) to prevent proliferation in advance. Next, $1 \times 10^{5} /$ well
SHEDs or BMMSCs (passage 6) were cultured in complete RPMI 1640 culture medium (Invitrogen) supplemented with $10 \%$ FBS, $2 \mathrm{mM}$ glutamine, $100 \mathrm{U} / \mathrm{ml}$ penicillin, and streptomycin, and allowed to adhere for $2 \mathrm{~h}$ at $37^{\circ} \mathrm{C}$ and $5 \% \mathrm{CO}_{2}$. Then, $1 \times 10^{6}$ PBMCs were seeded onto the cultured MSCs in the presence of $5 \mu \mathrm{g} /$ ml phytohemagglutinin (PHA; Sigma). PBMCs cultured alone with or without PHA served as controls. After 3 days, the suspended PBMCs were collected for flow cytometry analysis. The supernatant of cell cultures was collected and kept at $-80^{\circ} \mathrm{C}$ for later examination with ELISA.

\section{Lymphocyte proliferation assay}

The effects of SHEDs and BMMSCs on lymphocyte proliferation were examined using carboxyfluorescein diacetate succinimidyl ester (CFSE; BD Biosciences) labeling $(n=5)$. Briefly, PBMCs were resuspended and labeled with CFSE $(5 \mu \mathrm{M})$ for $10 \mathrm{~min}$ at $37^{\circ} \mathrm{C}$ and $5 \% \mathrm{CO}_{2}$. Then, $1 \times 10^{6}$ CFSE-labeled PBMCs were then seeded into a set of wells containing diminishing numbers of MSCs $\left(1 \times 10^{4} /\right.$ well SHEDs, $2 \times 10^{4} /$ well SHEDs, $1 \times 10^{5}$ / well SHEDs, and $1 \times 10^{5} /$ well BMMSCs) in the presence of $5 \mu \mathrm{g} / \mathrm{ml}$ PHA. CFSE-labeled PBMCs cultured alone with or without PHA served as controls. After 3 days of culture, gated $\mathrm{CD}^{+} \mathrm{T}$ cells in PBMCs were analyzed using a FACS Calibur flow cytofluorimeter (BD Biosciences). The percentages of mean fluorescent intensity (MFI) were used to reflect the proliferation of $\mathrm{T}$ lymphocytes.

\section{Cytokine measurement assay}

The concentrations of human IFN- $\gamma$, IL-4, IL-10, IL-17A, prostaglandin-E2 $\left(\mathrm{PGE}_{2}\right)$, and transforming growth factor beta 1 (TGF- $\beta_{1}$ ) in the supernatant of the coculture systems were examined using ELISA kits (IFN- $\gamma$, IL-4, IL-10, IL-17A: BD Biosciences; PGE 2 : R\&D System, Minneapolis, MN, USA; TGF- $\beta_{1}$ : Thermo Fisher, Waltham, MA, USA) in accordance with the manufacturer's instructions.

\section{Flow cytometry analysis}

Flow cytometry analysis was performed to identify Treg cells. Cells were stained with fluorescein isothiocyanate (FITC)-labeled anti-CD4 antibodies (Abs) and allophycocyanin (APC)-labeled anti-CD25 Abs (BD Biosciences) and then fixed and permeabilized using a fix/perm solution (BD Biosciences) according to the manufacturer's instructions. The cells were then incubated with phycoerythrin (PE)-labeled anti-Foxp3 Abs (BD Biosciences), and an isotype-matched control was used to determine the background. The data were evaluated using FlowJo software (version 7.6; Treestar, Inc., St Ashland, OR, USA). 


\section{Cytokine neutralization assay}

To identify the possible pathway involved in the immune regulation of SHEDs on T lymphocytes, coculture systems of PBMCs and SHEDs were treated with indomethacin $\left(10 \mu \mathrm{M}\right.$; Sigma) to block the $\mathrm{PGE}_{2}$ pathway through the inhibition of cyclooxygenase (COX) or anti-TGF- $\beta$ $\mathrm{Ab}$ (BD Biosciences), respectively, for the neutralization of soluble TGF- $\beta_{1}$. Treg expansion was detected via flow cytometry, and $\mathrm{T}$ lymphocyte proliferation was evaluated by CFSE labeling $(n=5)$.

\section{Statistical analysis}

Data are represented as the mean \pm SD from three independent experiments. Statistical significance was assessed by Student's $t$ test or ANOVA using SPSS software 23.0 (SPSS Inc., Chicago, IL, USA) and GraphPad Prism 7.0 (GraphPad, San Diego, CA, USA). A $p$ value < 0.05 was considered significant.

\section{Results}

SHEDs reduce nasal inflammation in an AR mouse model

To assess the anti-inflammatory effects of SHEDs on allergic symptoms, we injected SHEDs into an AR mouse model via the tail vein. First, we counted the sum of sneezing and nasal rubbing events in $10 \mathrm{~min}$ after the final challenge. As illustrated in Fig. 2A, the number of sneezing and rubbing events was significantly higher in the OVA group than in the control group and sham-SHED group $(p<.001)$. The nasal symptoms of mice were obviously relieved after the injection of MSCs. There was no significant difference between the BMMSC group and the SHED group at the same injection dose.

We qualitatively and quantitatively evaluated the effect of SHED treatment on the histopathology of the nasal mucosa (Fig. 2B, C). The pathological manifestations of AR mainly include eosinophil and T lymphocyte infiltration. T lymphocytes, especially Th2 cells, can release cytokines and recruit inflammatory cells. Eosinophils can release cellular content, cause tissue damage, and promote inflammation progress. According to our results, nearly no inflammatory cell was observed in the nasal mucosa of the control and sham-SHED groups. In contrast, the OVA group exhibited obvious eosinophil infiltration, goblet cell hyperplasia, and $\mathrm{T}$ lymphocyte infiltration in the nasal mucosa. Interestingly, the numbers of eosinophils were significantly decreased in the SHED and BMMSC groups compared to the OVA group (both $p<.001$ ). Meanwhile, the positive-goblet cell and $\mathrm{T}$ lymphocyte infiltration were significantly alleviated upon MSC administration. It demonstrated that SHEDs have the ability to inhibit the development of allergic inflammation. In addition, the inflammatory reaction in the SHED group was much lighter than that in the BMMSC group $(p<.001)$.

\section{SHEDs regulate the secretion of immunoglobulin in an AR mouse model}

Since immunoglobulins play an important role in regulating the inflammatory response, the expression of several OVA-specific immunoglobulin antibodies was determined. As illustrated in Fig. 3a, we confirmed a significant elevation in the serum levels of OVA-specific IgE, IgG ${ }_{1}$, and $\operatorname{IgG}_{2 \mathrm{a}}$ in the OVA group compared with the control and sham-SHED groups $(p<.05)$. Interestingly, systemic administrations of SHEDs and BMMSCs resulted in a decrease in serum OVA-specific IgE and $\mathrm{IgG}_{1}$ in comparison with the OVA group (SHED: $p$ $=.002$ and $p<.001$; BMMSC: $p=.018$ and $p<.001)$ but not $\operatorname{IgG}_{2 \mathrm{a}}$ (SHED: $p=.419$; BMMSC: $p=.901$ ). The downregulation of IgE and $\operatorname{IgG}_{1}$ in the SHED group was not different from that in the BMMSC group at the same injection dose ( $p=.356$ and $p=.188$, respectively).

\section{SHEDs change the cytokine levels in the splenic lymphocyte culture system}

To determine whether injected SHEDs affect cytokine production, a lymphocyte restimulation test was performed (Fig. 3b). IFN- $\gamma$, IL-4, IL-5, IL-13, and IL-17A levels in the supernatant of OVA-incubated splenocytes were significantly higher in the OVA group than in the control group and sham-SHED group $(p<.001)$. IL- 4 , IL-5 IL-13 and IL-17A levels were significantly reduced upon SHED and BMMSC administration (SHED: $p$ $<.001, p<.001, p<.001, p=.008$, respectively; BMMSC: $p=.008, p=.012, p=.002, p=.023$, respectively). In contrast, the levels of IFN- $\gamma$ in the supernatant were significantly higher in the SHED and BMMSC treatment groups compared with the OVA group (SHED: $p=.009$; BMMSC: $p=.027)$. The downregulation of IL-4 and IL-13 in the SHED group was more obvious than that in the BMMSC group at the same dose $(p=.031$ and $p$ $=.033$, respectively).

\section{Effect of SHEDs on mRNA expression}

To further evaluate the effects of SHED administration on allergic inflammation, we measured the relative expression of mRNAs encoding Th1, Th2, Th17, and Treg cell-related cytokines and specific transcription factors using real-time PCR (Fig. 4). The relative mRNA expression levels of IL- 4 and GATA- 3 were significantly higher in the OVA group than in the control group and sham-SHED group and were downregulated upon treatment with MSCs (SHED: $p<.001$ for both; BMMSC: $p<.001$ and $p=.018$ ). The levels of mRNAs encoding IFN- $\gamma$ and T-bet increased in both the SHED group $(p<.001$ and $p=.017$, respectively) and the BMMSC 


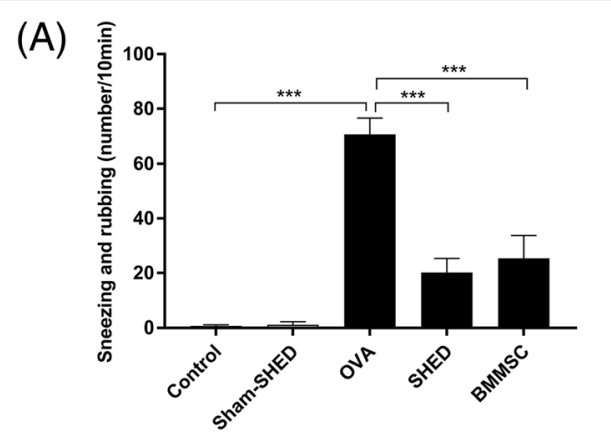

(B)

(C)
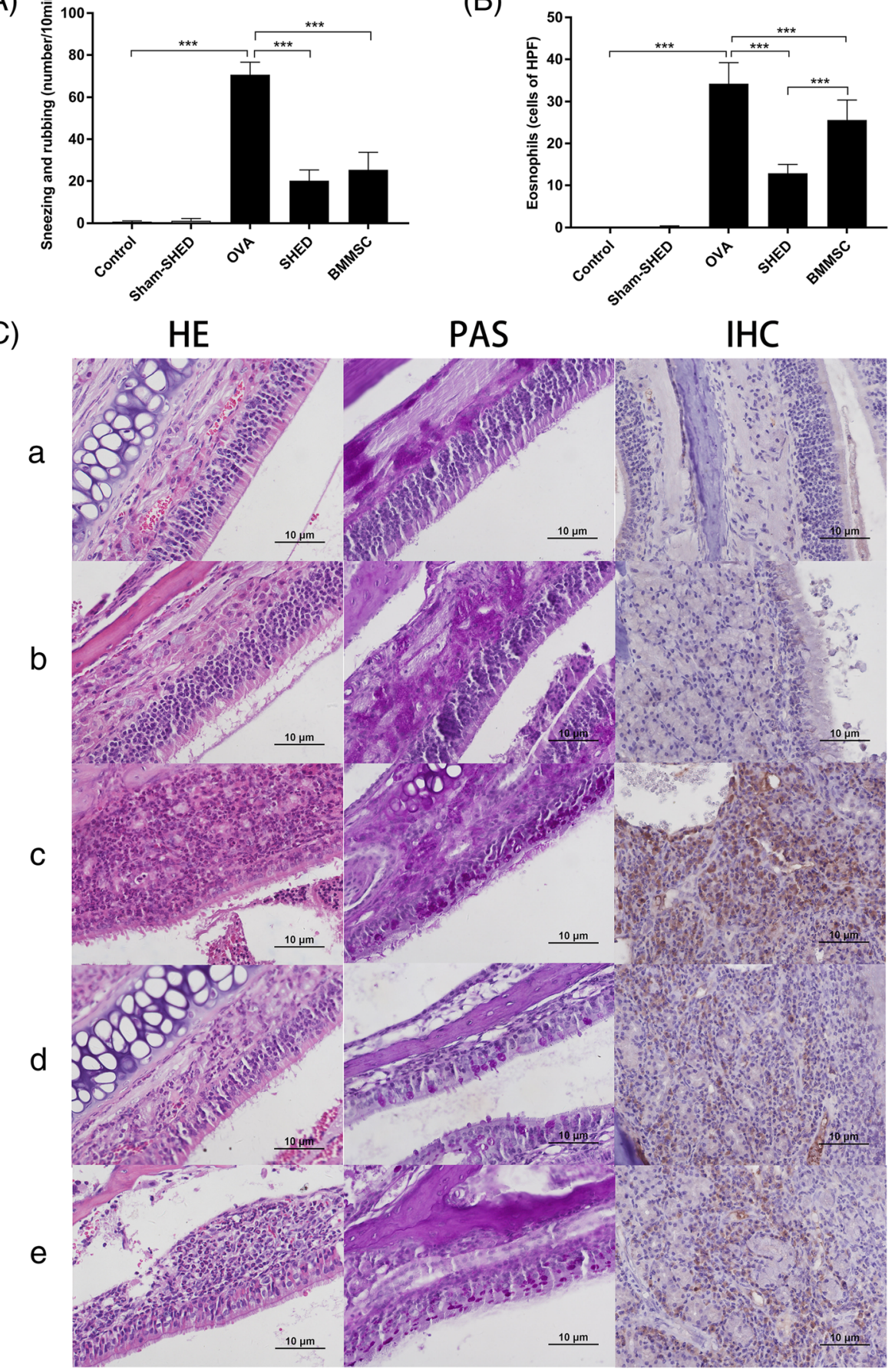

Fig. 2 Effect of SHED on nasal inflammation. A The nasal symptoms were evaluated by the number of sneezing and rubbing events in 10 min after the final challenge. Nasal symptoms in the OVA group were much more serious than those in the control group and sham-SHED group but were relieved after SHED and BMMSC treatment. B, C Twenty-four hours after the last challenge, HE staining, PAS staining, and IHC were used to reflect the inflammatory infiltration in the nasal mucosa. The numbers of eosinophils were evaluated under a light microscope ( $\times 400$ magnification). Nearly no inflammatory cells were observed in the control group (a) and sham-SHED group (b). In contrast, the OVA group (c) exhibited obvious eosinophil infiltration, goblet cell hyperplasia, and T lymphocyte infiltration. The inflammatory infiltration in the SHED group (d) and BMMSC group (e) was significantly alleviated compared with the OVA group, and the eosinophil count in the SHED group was lower than that of the BMMSC group. Data are expressed as the mean $\pm S D$ ( $n=6$ in each group) from three representative experiments. ${ }^{* *} p<.001$ 


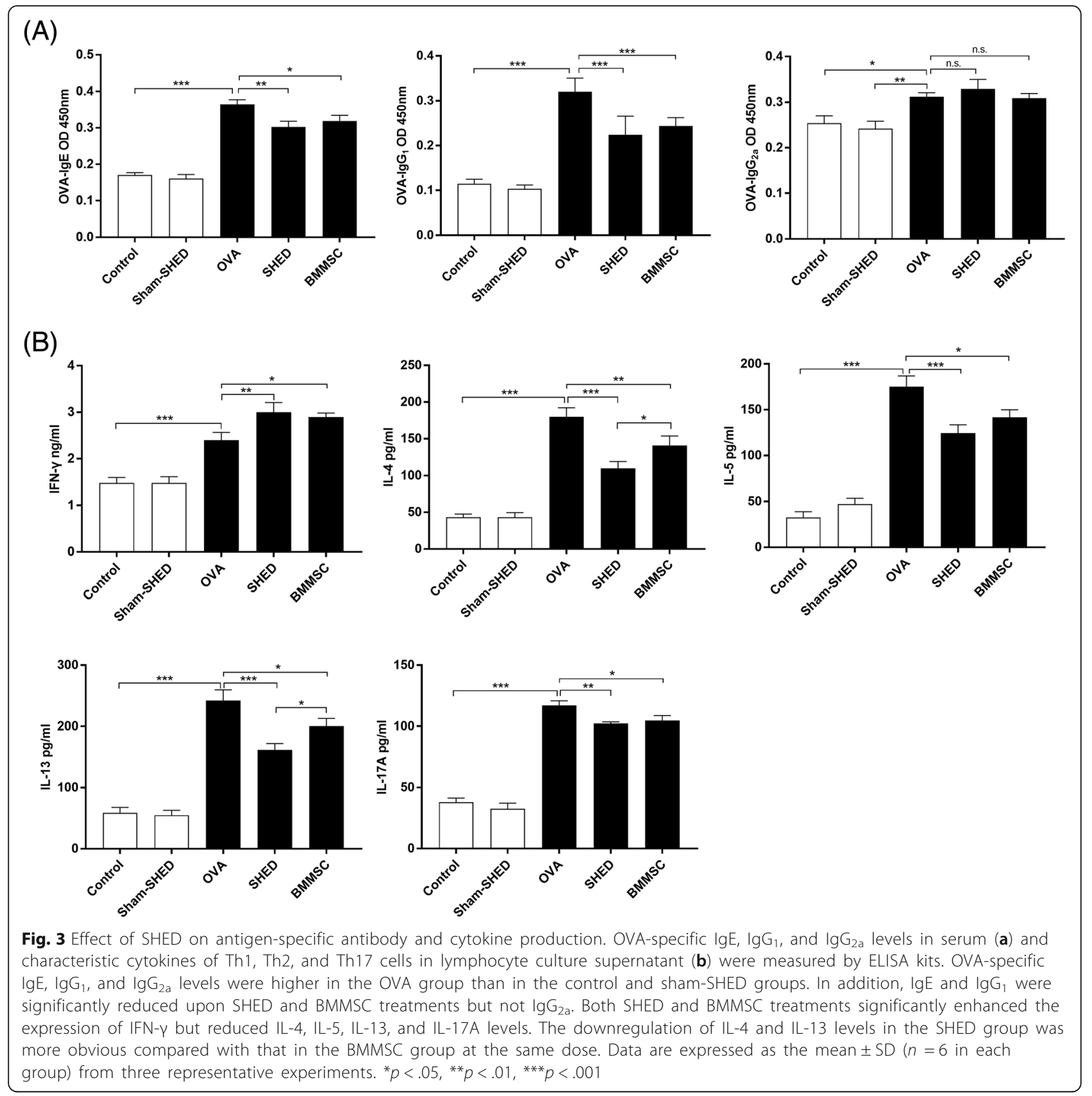

group ( $p=.002$ and $p=.014$, respectively) in contrast to those in the OVA group. Additionally, SHED and BMMSC treatment reduced the mRNA expression of IL-17A in splenic lymphocytes $(p=.012$ and $p=.02$, respectively). However, RORyt expression in the SHED and BMMSC groups showed no significant change compared with that in the OVA group (SHED: $p=.53$; BMMSC: $p=.303)$. Furthermore, the relative mRNA expression levels of Foxp3 were significantly decreased in the OVA group compared to the control group $(p=.006)$ and were upregulated with the treatment of SHEDs $(p<.001)$ and BMMSCs $(p=.001)$. The abilities of SHEDs in reducing IL-4 and GATA-3 were stronger than those of BMMSCs $(p=.006$ and $p=.003$, respectively).

\section{SHEDs inhibit T lymphocyte proliferation in AR patients}

To explore the immunomodulatory effect of SHEDs on $\mathrm{T}$ lymphocytes, a lymphocyte proliferation assay was performed in the CFSE experiment. As illustrated in Fig. 5, we found that the percentages of $\mathrm{T}$ lymphocyte proliferation decreased with an increasing SHED to PBMC ratio, suggesting that SHEDs significantly inhibited the proliferation of $\mathrm{CD}^{+} \mathrm{T}$ cells in a dose-dependent manner. 

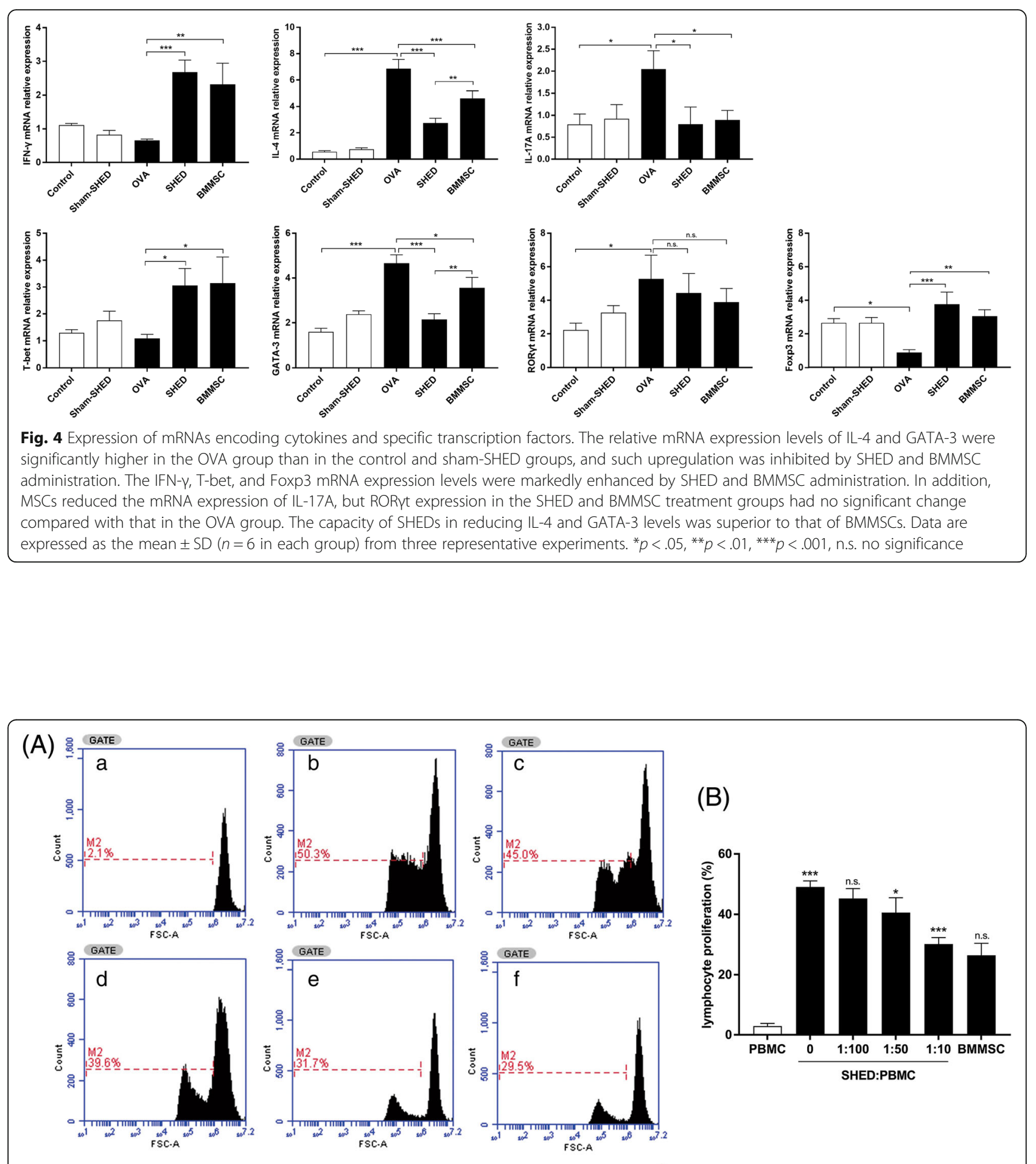

(B)

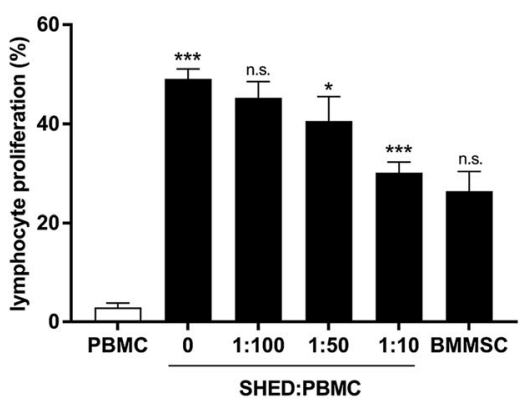

\section{CFSE}

Fig. 5 The immunosuppressive effect of SHEDs on PHA-stimulated lymphocyte proliferation. A CFSE-labeled PBMCs from AR patients $\left(1 \times 10^{6} /\right.$ well) were stimulated by PHA $(5 \mu \mathrm{g} / \mathrm{ml})$ in a 24-well plate for 3 days in the presence or absence of different numbers of SHEDs or BMMSCs $(n=5)$. PBMCs were gated for flow cytometry analysis of $\mathrm{CD}^{+}$staining. B Representative results of T cell proliferation without stimulation (a), PHA (5 $\mu \mathrm{g} /$ $\mathrm{ml})$ stimulation (b), and PHA stimulation in the presence of SHEDs $\left(1 \times 10^{4} /\right.$ well, c), SHEDs $\left(2 \times 10^{4} /\right.$ well, d), SHEDs $\left(1 \times 10^{5} /\right.$ well, d), or BMMSCs $\left(1 \times 10^{5} /\right.$ well, e) are shown. SHEDs significantly inhibited PHA-stimulated lymphocyte proliferation in a number-dependent manner, as determined by lymphocyte proliferation percentages. BMMSCs also inhibited T lymphocyte proliferation, but there was no significant difference with SHED at the same dose. The data are expressed as the mean \pm SD. ${ }^{*} p<.05$, ${ }^{* * *} p<.001$, n.s. no significance, compared with group on the left 
BMMSCs inhibited PHA-stimulated T cell proliferation as well, but there was no significant difference in inhibition ability between SHED and BMMSC under the same culture conditions.

\section{SHEDs alter cytokine production in PHA-stimulated PBMCs of AR patients}

To further investigate the immunomodulatory effects of SHEDs on the $T$ cell phenotype, we next examined the effects of SHEDs and BMMSCs on cytokine production in the supernatant using ELISA kits (Fig. 6a). Compared with the culture of PHA-stimulated PBMC, the levels of IFN- $\gamma$ and IL-10 were significantly increased $(p=.003$, $p=.006$, respectively), and the levels of IL- 4 and IL-17A were decreased upon the presence of SHEDs $(p=.012$ and $p<.001$, respectively). Although IL-10 was increased and IL-17A was markedly decreased after the addition of BMMSCs ( $p=.047$ and $p=.006$, respectively), there was no significant difference in the levels of IFN- $\gamma$ and IL-4 between the BMMSC coculture system and the PHA-stimulated PBMC $(p=.326$ and $p=.294$, respectively).

Moreover, MSCs could regulate immune response by secreting soluble factors, such as $\mathrm{PGE}_{2}$ and TGF- $\beta_{1}$. In our results, the levels of $\mathrm{PGE}_{2}$ and TGF- $\beta_{1}$ were increased in the supernatant of SHED or BMMSC coculture system compared to those in the culture of PHA-stimulated PBMC without MSCs $\left(\mathrm{PGE}_{2}\right.$, both $p<.001$; TGF- $\beta_{1}, p<.001$ and $p=.002$, respectively). Significant differences were detected in the levels of $\mathrm{PGE}_{2}$ and TGF- $\beta_{1}$ between the cultures of SHED and BMMSC ( $p=.009$ and $p=.045$, respectively).

\section{SHEDs enhance $\mathrm{CD} 4^{+} \mathrm{CD} 25^{+} \mathrm{Fxop}^{+}{ }^{+}$Treg cell expansion}

The effects of SHEDs and BMMSCs on Treg expansion in restimulated PBMCs were determined using flow cytometry. As illustrated in Fig. 6b, we found that both SHEDs and BMMSCs significantly increased the ratio of $\mathrm{CD} 4^{+} \mathrm{CD} 25^{+} \mathrm{Foxp}^{+}$Tregs in the $\mathrm{CD}^{+}$subpopulation $(p<.001)$. Interestingly, the increase in Foxp $3^{+}$Treg frequency in the SHED group was higher than that in the BMMSC group $(p=.026)$.

\section{TGF- $\beta_{1}$ neutralization downregulates Treg cells in AR patients}

As illustrated in Fig. 7, after neutralizing TGF- $\beta_{1}$, the percentage of Tregs in flow cytometry was significantly decreased in contrast to the SHED group, and the percentage of MFI in the T lymphocyte proliferation test correspondingly increased $(p=.014$ and $p=.046$, respectively). However, these changes were not significant after blocking $\mathrm{PGE}_{2}(p=.531$ and $p=.484$, respectively), which suggested that TGF- $\beta_{1}$ neutralization, but not PGE2 blockage, could partly relieve the immunomodulatory effect of SHEDs on T lymphocytes though changing Treg expansion.

\section{Discussion}

MSCs have been revealed to possess immunomodulatory capacity in vitro and vivo, which significantly alleviates the inflammatory response in allergic diseases [15]. Due to the low expression of major histocompatibility complex class I (MHC I) and the negative expression of major histocompatibility complex class II (MHC II) [16], we transplanted xenogeneic SHEDs into an AR mouse model to explore the immunomodulatory effect compared with that of BMMSCs. In addition, coculture systems of MSCs and PBMCs from AR patients were established to determine the underlying mechanism.

The immunological basis of AR pathogenesis is the decrease of Th1/Th2 ratio. Hence, correcting the imbalance is the key to AR treatment [17]. In the present study, we demonstrated that xenogeneic MSCs downregulated the Th2 inflammatory response and relieved nasal symptoms and inflammation (eosinophil infiltration, goblet cell hyperplasia, and $\mathrm{T}$ lymphocyte infiltration). Both SHEDs and BMMSCs significantly reduced the levels of IL-4, IL-5, and IL-13 (representing the Th2 phenotype) in splenic lymphocytes and decreased the production of $\operatorname{IgE}$ and $\operatorname{IgG}_{1}$ in serum. The relative mRNA expression of IL-4 and GATA-3 was reduced upon MSC injection, which reflected the immunosuppression effect from another aspect. In contrast, SHEDs and BMMSCs upregulated the level of IFN $-\gamma$ and the relative mRNA expression of IFN- $\gamma$ and T-bet (representing the Th1 phenotype), suggesting that MSCs could shift the Th2 to Th1 immune response and increase the ratio of Th1/Th2. The above data were consistent with previous studies involving BMMSCs and adipose mesenchymal stem cells (ASCs) $[5,7,18]$.

Th17 cells involved in neutrophil and macrophage infiltration are closely related to the initiation and progression of AR [19]. Yamaza et al. [20] found that SHEDs had significant effects on inhibiting Th17 cells in vitro. A recent study also showed that ASCs reduced the IL-17 levels of bronchoalveolar lavage fluid (BALF) and serum in OVA-induced asthma models and suppressed the relative mRNA expression of IL-17 and RORyt in lung tissue [21]. According to our results, although the mRNA expression of ROR $\gamma t$ did not change, the levels of IL-17A and mRNA expression of IL-17A in the spleen decreased significantly after MSC transplantation, suggesting that both SHEDs and BMMSCs inhibited the activity of Th17 cells in AR mice and delayed the development of disease.

Moreover, Treg cells characterized by intracellular expression of the transcription factor Foxp3 have been identified as having suppressor functions, which are essential 

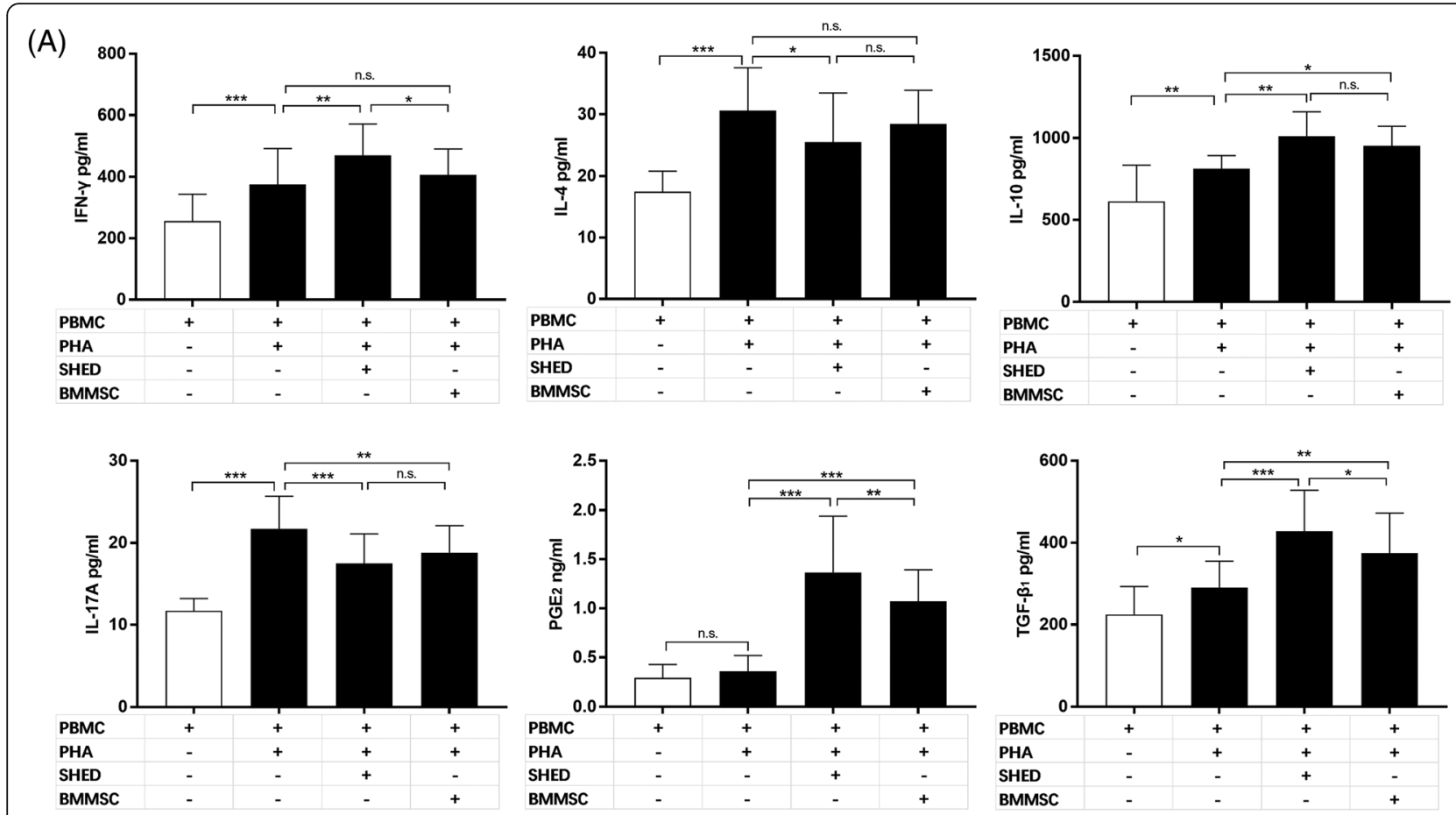

(B)

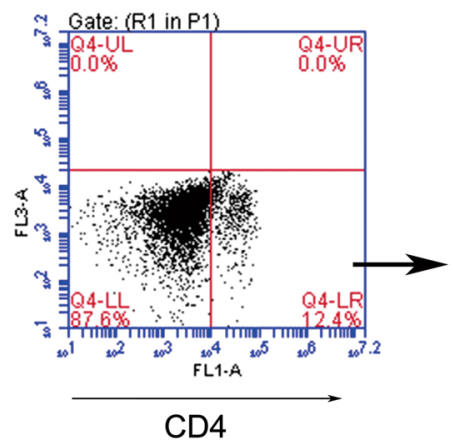

PBMC

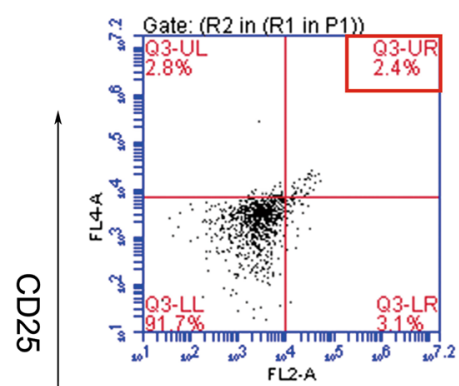

$\mathrm{PBMC}+\mathrm{PHA}$

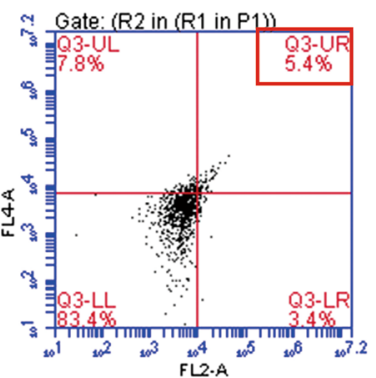

$\mathrm{PBMC}+\mathrm{PHA}+\mathrm{SHED}$
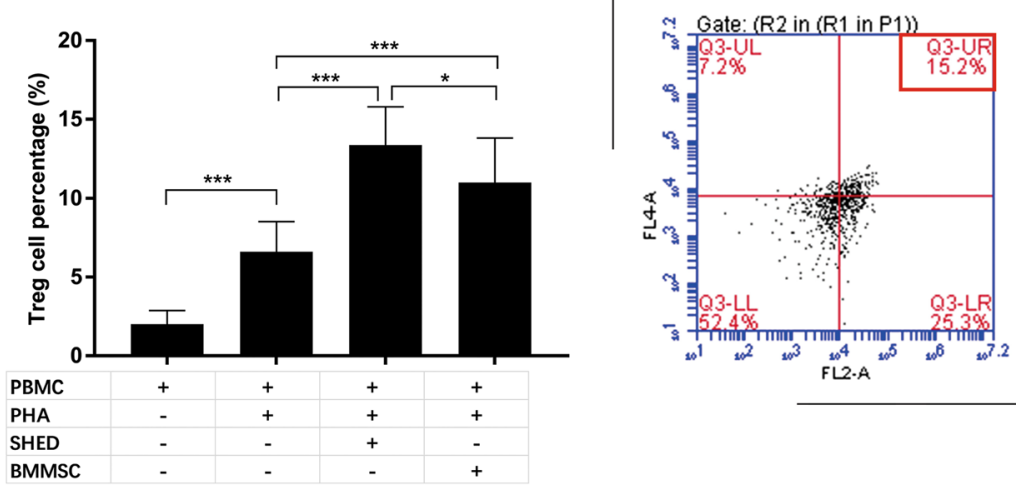

$\mathrm{PBMC}+\mathrm{PHA}+\mathrm{BMMSC}$

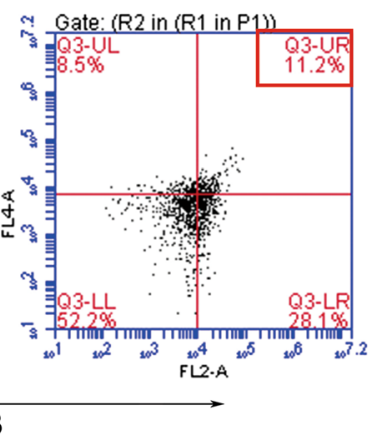

Fig. 6 SHED corrected the immune imbalance and promoted the expansion of $C D 4^{+} C D 25^{+}$Foxp3 ${ }^{+}$Treg cells in vitro. a The addition of SHEDs led to the downregulation of IL-4 and IL-17 levels and the upregulation of IFN- $\gamma$, IL-10, PGE , and TGF- $\beta_{1}$ levels. Although BMMSCs showed similar immunomodulation ability, the levels of IFN- $y$ and IL-4 were not significantly different from those of the PHA-stimulated PBMC $(n=10)$. $\mathbf{b}$ In addition, both SHEDs and BMMSCS upregulated the proportion of $\mathrm{CD} 4^{+} \mathrm{CD} 25^{+}$Foxp3 ${ }^{+}$Treg cells in $\mathrm{CD} 4^{+}$subsets compared to the PHA-stimulated PBMC group, and the ratio of Treg cells in the SHED group was significantly higher than that in the BMMSC group $(n=5)$. The data are expressed as the mean \pm SD. ${ }^{*} p<.05,{ }^{* *} p<0.01,{ }^{* * *} p<.001$, n.S. no significance 


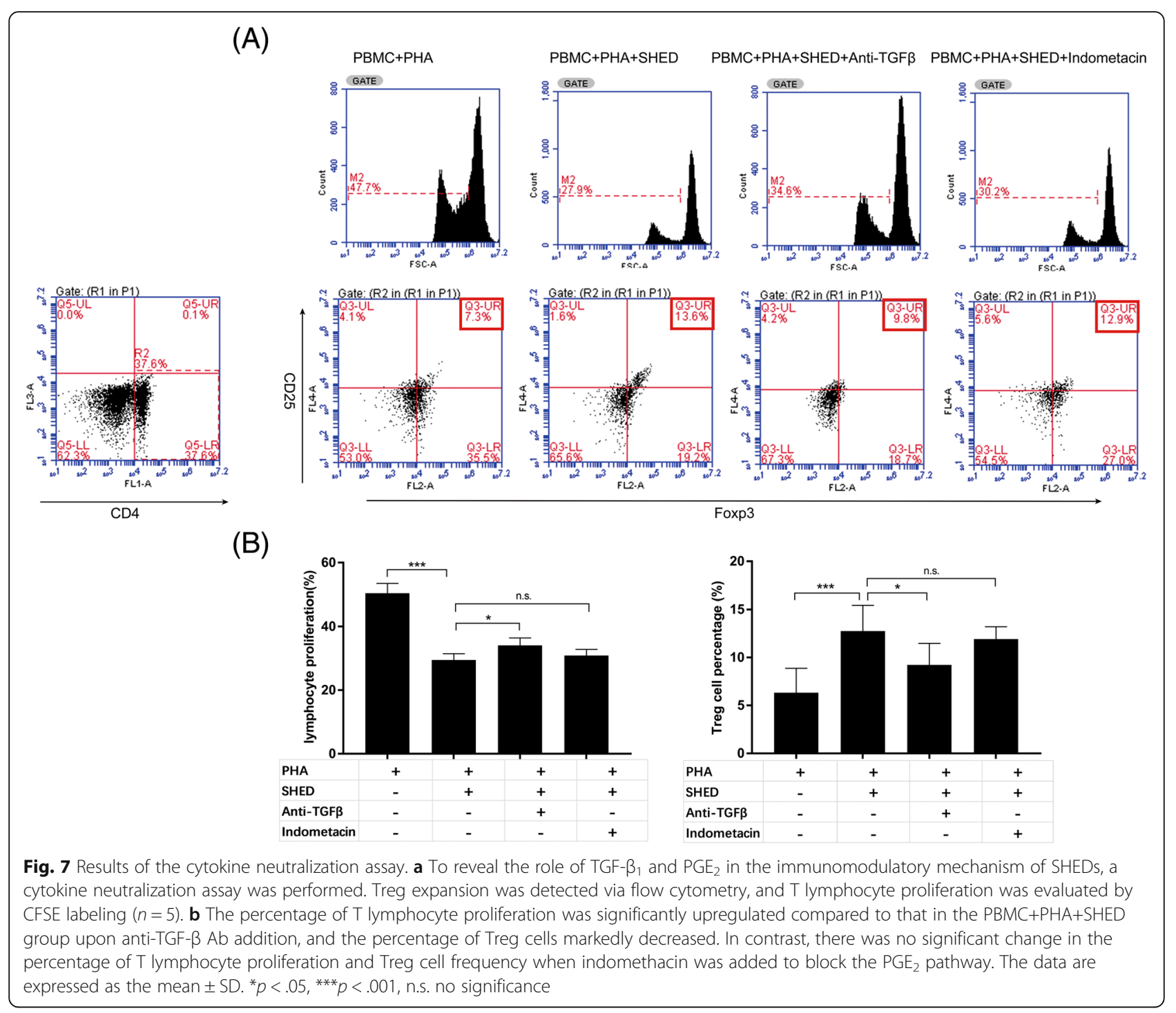

for the resolution of inflammatory processes $[15,22]$. Numerous studies have shown the upregulation of Treg cell numbers and activity after the administration of MSCs in asthma models [23, 24]. Similarly, our in vivo study found that Foxp3 mRNA expression in splenic lymphocytes significantly increased in MSC groups compared to the OVA group, providing evidence that SHEDs and BMMSCs play anti-inflammatory roles through Foxp $3^{+}$Treg expansion in mouse models of AR.

It was acknowledged that MSCs suppressed the immune response by inhibiting $\mathrm{T}$ cell proliferation, whether in a mitogen- or allergen-stimulated culture system $[25,26]$. To further explore the ability of inhibiting $\mathrm{T}$ cell proliferation in vitro, SHEDs and BMMSCs were cocultured in PBMCs from AR patients respectively. Likewise, in our study, we found that SHEDs inhibited $\mathrm{CD}^{+} \mathrm{T}$ cell proliferation by decreasing the division percentage in a dose-dependent manner compared to that of PHA-stimulated PBMCs alone. In addition, the decrease in IL-4 and IL-17A and the increase in IFN- $\gamma$ in the supernatant suggested that SHEDs could increase Th1/Th2 ratio and correct the immune imbalance of AR in vitro. Some studies showed that the level of IFN- $\gamma$ was decreased after coculture of MSCs with PBMCs from healthy subjects, which was contrary to our results $[27,28]$. As the immunosuppressive properties of MSCs were not inflexible but were induced by environmental inflammatory mediators [29], we attribute these contrasting results to the different modulatory effects of MSCs on Th1- or Th2-mediated responses.

The protection afforded by MSCs in allergic disease is mediated through multiple mechanisms (soluble factors, cell-to-cell contact, regulatory $\mathrm{T}$ cells, induction of anergy, apoptosis, etc.), which in the end lead to the induction or expansion of active Tregs and the generation of tolerance [30-32]. Furthermore, the promotion of Tregs by MSCs in vitro required cell-cell contact as well as 
$\mathrm{PGE}_{2}$ and TGF- $\beta_{1}$. Cell contact between MSCs and activated $\mathrm{T}$ cells induces IL-10 production, which plays an essential role in promoting the generation of Treg cells $[33,34]$. The soluble factors TGF- $\beta_{1}$ and $\mathrm{PGE}_{2}$ are regarded as the main inducers of Treg cell subsets during the differentiation process of $\mathrm{T}$ helper lymphocytes [35]. Cho et al. showed that blocking $\mathrm{PGE}_{2}$ and neutralizing TGF- $\beta_{1}$ eliminated the immunosuppressive effect of ASCs [24]. Genç et al. stated that human dental pulp MSCs enhanced $\mathrm{CD} 44^{+} \mathrm{CD} 25^{+}$Foxp $3^{+}$Treg frequency and demonstrated that blockade of TGF- $\beta_{1}$ resulted in decreased $\mathrm{T}$ regulatory cell frequency [28]. In accordance with previous studies, Treg cell frequencies were increased in both SHED and BMMSC coculture systems, accompanied by the upregulation of IL-10, TGF- $\beta_{1}$, and $\mathrm{PGE}_{2}$ levels. In addition, neutralizing TGF- $\beta_{1}$ downregulated Treg cell frequency in contrast to SHEDs cocultured without blockade, leading to the partial relief of the proliferation inhibition of $\mathrm{CD}^{+}{ }^{+} \mathrm{T}$ cells, which suggested that the change in TGF- $\beta_{1}$ might be the potential pathway of SHEDs promoting Treg expansion. However, blocking of $\mathrm{PGE}_{2}$ did not significantly change the frequency of Treg cells and T lymphocyte proliferation, which indicated that the suppressive mechanism of SHEDs might not be mediated through $\mathrm{PGE}_{2}$. Even so, we cannot completely deny the role of $\mathrm{PGE}_{2}$ in SHED immunomodulation. MSC-mediated immunoregulation is a redundant system that is mediated by several molecules, and inhibition of any one of these molecules does not result in a complete loss of the immunosuppressive activity of MSCs.

In this study, we compared the immunomodulatory function of SHEDs and BMMSCs in parallel. In vivo, SHEDs were superior to BMMSCs in inhibiting the Th2 immune response (downregulation of IL-4 and IL-13 and mRNA expression of IL-4 and GATA-3) and inflammatory infiltration of nasal mucosa. In vitro, although there was no difference between SHEDs and BMMSCs in the inhibition of $\mathrm{T}$ lymphocyte proliferation, the ability of SHEDs to induce the expansion of Treg cells was superior to that of BMMSCs. Moreover, we found an interesting phenomenon in our research. In vitro, the cytokine levels were all significantly changed in SHED coculture system. However, in BMMSC coculture system, even the levels of IFN- $\gamma$ and IL-4 showed a change tendency, there was no statistical significance compared with the positive control group. This results suggested that SHEDs could achieve the effect of cytokine regulation under the present condition, while BMMSCs might need a larger proportion of cells than 1:10 (MSC to PBMC) or a lower cell passage. According to the above analysis and considering the convenience of SHED acquisition, no ethical issues, and the ability of proliferation, we believe that SHEDs may have more advantages in the application of AR therapy than BMMSCs.
We acknowledge the limitations of this study. For example, it may be more persuasive to investigate the immunoregulation effect of MSCs in mouse splenic lymphocytes directly. However, we chose to use PBMCs from AR patients for the aim of clinical transformation. Second, a transwell assay is suggested to be used to detect the role of cell-to-cell contact on the immunoregulatory capacity of SHED. At last, a coculture assay of higher ratios of MSC to PBMC or lower cell passages need to be performed in the follow-up study.

\section{Conclusions}

SHEDs reduced nasal inflammation, suppressed the Th2-driven response, and corrected the $\mathrm{CD} 4^{+} \mathrm{T}$ cell immune imbalance in a mouse model of $A R$. In vitro, SHEDs inhibited the proliferation of $\mathrm{T}$ lymphocytes and increased the ratio of Th1/Th2 by inducing the expansion of Treg cells. Furthermore, the neutralization of TGF- $\beta_{1}$ inhibited the immunomodulatory effect of SHEDs, suggesting that TGF- $\beta_{1}$ plays a crucial role in the underlying mechanism. These results suggest that SHEDs have excellent immunomodulation ability and may be potential therapeutic agents for the treatment of allergic diseases such as AR in the future.

\section{Additional file}

Additional file 1: Table S1. Corresponding primers designed for quantitative real-time PCR in this study. (DOC $35 \mathrm{~kb}$ )

\section{Abbreviations}

APC: Allophycocyanin; AR: Allergic rhinitis; ARIA: Allergic Rhinitis and its Impact on Asthma; ASC: Adipose mesenchymal stem cell; BALF: Bronchoalveolar lavage fluid; BMMSC: Bone marrow mesenchymal stem cell; CFSE: Carboxyfluorescein diacetate succinimidyl ester; COX: Cyclooxygenase; DMEM/F12: Dulbecco's modified Eagle's medium/ nutrient f-12 ham; FBS: Fetal bovine serum; FITC: Fluorescein isothiocyanate; IFN: Interferon; IHC: Immunohistochemistry; IL: Interleukin; MFI: Mean fluorescent intensity; MHC I: Major histocompatibility complex class I; MHC II: Major histocompatibility complex class II; mRNA: Messenger RNA; MSC: Mesenchymal stem cell; OVA: Ovalbumin; PAS: Periodic acid-Schiff; PBMC: Peripheral blood mononuclear cell; PE: Phycoerythrin; $\mathrm{PGE}_{2}$ : Prostaglandin-E2; PHA: Phytohemagglutinin; SHED: Stem cell from human exfoliated deciduous teeth; TGF- $\beta_{1}$ : Transforming growth factor beta 1; a-MEM: Alpha modification of Eagle's medium

\section{Acknowledgements}

The authors would like to thank all patients and otolaryngologists from Department of Otorhinolaryngology Head and Neck Surgery, Beijing Tongren Hospital (Beijing, China) for their contributions to this study. In addition, the authors are very grateful to Dr. Jiamin Chen from Beijing Ditan Hospital (Beijing, China) for support in the pathological analysis.

\section{Funding}

This work was supported by the National Science and Technology Major Project of China (2011ZX09302-007-05).

\section{Availability of data and materials}

The datasets used and/or analyzed during the study are available from the corresponding author on reasonable request. 


\section{Authors' contributions}

YYD contributed to the study design, animal modeling, clinical sample collection, cytokine detection, flow cytometry, and manuscript writing. SYN contributed to the data collection and statistical analysis. KM contributed to the study design and animal modeling. YSM and ZSW contributed to the cell culture and data collection. XLZ contributed to concept and design, manuscript writing, and final approval of manuscript. All authors read and approved the manuscript.

\section{Ethics approval and consent to participate}

The animal study protocol was approved by the Institutional Animal Care and Use Committee of Capital Medical University (AEEI-2018-075). The cell research was in compliance with the Helsinki declaration and was approved by the ethics committee of Beijing Tongren Hospital (TREC2018-KY01). The informed consent process was performed and informed consent form was signed by each patient.

\section{Consent for publication}

Not applicable

\section{Competing interests}

The authors declare that they have no competing interests.

\section{Publisher's Note}

Springer Nature remains neutral with regard to jurisdictional claims in published maps and institutional affiliations.

\section{Author details}

'National Institute for Drug Clinical Trial, Beijing Tongren Hospital, Capital Medical University, 1 Dongjiaominxiang Road, Beijing 100730, China. ${ }^{2}$ College of Chemical Biology and Pharmaceutical Sciences, Capital Medical University, 10 Xitoutiao Road, Beijing 100069, China. ${ }^{3}$ Beijing Institute of Ophthalmology, Beijing Tongren Eye Center, Beijing Tongren Hospital, Capital Medical University, 9 Chongwenmennei Road, Beijing 100005, China. ${ }^{4}$ Beijing Tason Biotech Co. Ltd., 10 PKUCare Industrial Park, Beijing 102206, China.

Received: 16 October 2018 Revised: 24 December 2018 Accepted: 3 January 2019 Published online: 22 January 2019

\section{References}

1. Meltzer EO, Blaiss MS, Derebery MJ, Mahr TA, Gordon BR, Sheth KK, Simmons AL, Wingertzahn MA, Boyle JM. Burden of allergic rhinitis: results from the Pediatric Allergies in America survey. J Allergy Clin Immunol. 2009; 12:443-70.

2. Uccelli A, Moretta $L$, Pistoia V. Mesenchymal stem cells in health and disease. Nat Rev Immunol. 2008;8:726-36.

3. Park HK, Cho KS, Park HY, Shin DH, Kim YK, Jung JS, Park SK, Roh HJ. Adipose-derived stromal cells inhibit allergic airway inflammation in mice. Stem Cells Dev. 2010;19:1811-8.

4. Le Blanc K, Frassoni F, Ball L, Locatelli F, Roelofs H, Lewis I, Lanino E, Sundberg B, Bernardo ME, Remberger M, Dini G, Egeler RM, Bacigalupo A, Fibbe W, Ringdén O; Developmental Committee of the European Group for Blood and Marrow Transplantation. Mesenchymal stem cells for treatment of steroid-resistant, severe, acute graft-versus-host disease: a phase II study. Lancet 2008;371:1579-1586.

5. Cho KS, Park HK, Park HY, Jung JS, Jeon SG, Kim YK, Roh HJ. IFATS collection: immunomodulatory effects of adipose tissue-derived stem cells in an allergic rhinitis mouse model. Stem Cells. 2010;27:259-65.

6. Samivel R, Kim EH, Chung YJ, Mo JH. Immunomodulatory effect of tonsilderived mesenchymal stem cells in a mouse model of allergic rhinitis. Am J Rhinol Allergy. 2015;29:262-7.

7. Ning Z, Liu Y, Liang H, Jiang X. Bone marrow-derived mesenchymal stem cells reduce immune reaction in a mouse model of allergic rhinitis. Am J Transl Res. 2016;8:5628-36.

8. Castromanrreza ME, Montesinos JJ. Immunoregulation by mesenchymal stem cells: biological aspects and clinical applications. J Immunol Res. 2015; 2015(2):394917.

9. Zongning $M$, Jun J, Lei $C$, et al. Isolation of mesenchymal stem cells from human placenta: comparison with human bone marrow mesenchymal stem cells. Cell Biol Int. 2013;30(9):681-7.
10. Miura M, Gronthos S, Zhao M, Lu B, Fisher LW, Robey PG, Shi S. SHED: stem cells from human exfoliated deciduous teeth. Proc Natl Acad Sci U S A. 2003;100:5807-12.

11. Suchánek J, Visek B, Soukup T, et al. Stem cells from human exfoliated deciduous teeth--isolation, long term cultivation and phenotypical analysis. Acta Med Austriaca. 2010;53(2):93-9.

12. Kim DY, Fukuyama S, Nagatake T, et al. Implications of nasopharynxassociated lymphoid tissue (NALT) in the development of allergic responses in an allergic rhinitis mouse model. Allergy. 2012;67(4):502-9.

13. Wee $\mathrm{JH}$, Zhang $\mathrm{YL}$, Rhee $\mathrm{CS}$, et al. Inhibition of allergic response by intranasal selective NF-KB decoy oligodeoxynucleotides in a murine model of allergic rhinitis. Allergy Asthma Immunol Res. 2017;9(1):61-9.

14. Bousquet J, Khaltaev N, Cruz AA, Denburg J, Fokkens WJ, Togias A, Zuberbier T, Baena-Cagnani CE, Canonica GW, van Weel C, et al. Allergic Rhinitis and its Impact on Asthma (ARIA) 2008 update (in collaboration with the World Health Organization, GA(2)LEN and AllerGen). Allergy. 2008;63:8-160.

15. Duffy MM, Ritter T, Ceredig R, Griffin MD. Mesenchymal stem cell effects on T-cell effector pathways. Stem Cell Res Ther. 2011;2:1-9.

16. Stagg J, Pommey S, Eliopoulos N, Galipeau J. Interferon-gamma-stimulated marrow stromal cells: a new type of nonhematopoietic antigen-presenting cell. Blood. 2006;107:2570-7.

17. Gould HJ, Sutton BJ. IgE in allergy and asthma today. Nat Rev Immunol. 2008;8:205-17.

18. Goodwin M, Sueblinvong $V$, Eisenhauer $P$, Ziats NP, LeClair L, Poynter ME, Steele C, Rincon M, Weiss DJ. Bone marrow-derived mesenchymal stromal cells inhibit Th2-mediated allergic airways inflammation in mice. Stem Cells. 2011;29:1137-48.

19. Umetsu DT, Dekruyff RH. The regulation of allergy and asthma. Immunol Rev. 2010;212:238-55.

20. Yamaza T, Kentaro A, Chen C, Liu Y, Shi Y, Gronthos S, Wang S, Shi S. Immunomodulatory properties of stem cells from human exfoliated deciduous teeth. Stem Cell Res Ther. 2010;1:5.

21. Dai R, Jia L, Cai S, Zheng C, Zhou X. Delivery of adipose-derived mesenchymal stem cells attenuates airway responsiveness and inflammation in a mouse model of ovalbumin-induced asthma. Am J Transl Res. 2017;9:2421-8.

22. Selmani Z, Naji A, Zidi I, Favier B, Gaiffe E, Obert L, Borg C, Saas P, Tiberghien P, Rouas-Freiss N, Carosella ED, Deschaseaux F. Human leukocyte antigen-G5 secretion by human mesenchymal stem cells is required to suppress T lymphocyte and natural killer function and to induce $\mathrm{CD}^{+}$CD25highFOXP3 ${ }^{+}$regulatory T cells. Stem Cells. 2010;26:212-22.

23. Kavanagh $H$, Mahon BP. Allogeneic mesenchymal stem cells prevent allergic airway inflammation by inducing murine regulatory T cells. Allergy. 2015;66: 523-31.

24. Cho KS, Lee JH, Park MK, Park HK, Yu HS, Roh HJ. Prostaglandin E2 and transforming growth factor- $\beta$ play a critical role in suppression of allergic airway inflammation by adipose-derived stem cells. PLoS One. 2015;10: e0131813.

25. Puissant B, Barreau C, Bourin P, Clavel C, Corre J, Bousquet C, Taureau C, Cousin B, Abbal M, Laharrague P, Penicaud L, Casteilla L, Blancher A Immunomodulatory effect of human adipose tissue-derived adult stem cells: comparison with bone marrow mesenchymal stem cells. $\mathrm{Br} J$ Haematol. 2015;129:118-29.

26. Chang CJ, Yen ML, Chen YC, Chien CC, Huang HI, Bai CH, Yen BL. Placentaderived multipotent cells exhibit immunosuppressive properties that are enhanced in the presence of interferon- $\gamma$. Stem Cells. 2010;24:2466-77.

27. Özdemir AT, Özgül Özdemir RB, Kırmaz C, Sarıboyacı AE, Ünal Halbutoğlları ZS, Özel C, Karaöz E. The paracrine immunomodulatory interactions between the human dental pulp derived mesenchymal stem cells and CD4 T cell subsets. Cell Immunol. 2016;310:108-15.

28. Genç D, Zibandeh N, Nain E, Gökalp M, Özen AO, Göker MK, Akkoç T. Dental follicle mesenchymal stem cells downregulate Th2-mediated immune response in asthmatic patients mononuclear cells. Clin Exp Allergy. 2018;48: 663-78.

29. Kim N, Cho SG. Overcoming immunoregulatory plasticity of mesenchymal stem cells for accelerated clinical applications. Int J Hematol. 2016;103:129-37.

30. English K. Mechanisms of mesenchymal stromal cell immunomodulation. Immunol Cell Biol. 2013;91:19-26.

31. Sakaguchi S, Wing K, Miyara M. Regulatory T cells - a brief history and perspective. Eur J Immunol. 2007;37:116-23. 
32. O'Garra A, Vieira P. Regulatory $T$ cells and mechanisms of immune system control. Nat Med. 2004;10:801-5.

33. Nasef A, Chapel A, Mazurier C, Bouchet S, Lopez M, Mathieu N, Sensebé L, Zhang Y, Gorin NC, Thierry D, Fouillard L. Identification of IL-10 and TGFbeta transcripts involved in the inhibition of T-lymphocyte proliferation during cell contact with human mesenchymal stem cells. Gene Expr. 2007; 13:217-26.

34. Yang SH, Park MJ, Yoon $\mathbb{H}$, Kim SY, Hong SH, Shin JY, Nam HY, Kim YH, Kim B, Park CG. Soluble mediators from mesenchymal stem cells suppress T cell proliferation by inducing IL-10. Exp Mol Med. 2009;41:315-24.

35. Kyurkchiev D, Bochev I, Ivanova-Todorova E, Mourdjeva M, Oreshkova T, Belemezova K, Kyurkchiev S. Secretion of immunoregulatory cytokines by mesenchymal stem cells. World J Stem Cells. 2014;6:552-70.

Ready to submit your research? Choose BMC and benefit from:

- fast, convenient online submission

- thorough peer review by experienced researchers in your field

- rapid publication on acceptance

- support for research data, including large and complex data types

- gold Open Access which fosters wider collaboration and increased citations

- maximum visibility for your research: over $100 \mathrm{M}$ website views per year

At BMC, research is always in progress.

Learn more biomedcentral.com/submissions 